\title{
A factor-analytic study of items to measure forethought development in children and adolescents
}

\author{
LINDA J. SANDHAM \\ University of Nebraska, Omaha, Nebraska \\ and \\ ROBERT A. HICKS \\ San Jose State University, San Jose, California
}

\begin{abstract}
To construct a preliminary scale to measure forethought development in children and adolescents, a pool of items that were thought to reflect the dimensions of forethought suggested by the existing literature was generated. A group of 300 boys and girls, ranging in age from 3 to 14 years, responded to this set of items. On the basis of factor-analytic results, a 41 -item forethought scale was developed. This scale is thought to measure three factors of forethought development: remote-future time comprehension, real-time consequences, and important future events. Reliability and validity measures will need to be obtained to confirm these findings. Together with the existing literature, our data suggest that future research should take into account the multidimensional nature of forethought development and focus on determing other predictors of this ability.
\end{abstract}

Forethought, that is, the ability to envision the future, is a symbolic ability that is essential to certain aspects of human cognitive and social functioning. Forethought is demonstrated in the limbic system, which, according to Cotman and McGaugh (1980), "confers our stability of purposeful behavior: our detailed schemes of conduct over time, our itineraries for life" (p. 49).

Forethought is an ability that may contribute to such self-regulating behaviors as planning, responsibility, and judgment (Cotman \& McGaugh, 1980). It may also be implicated in such uniquely human social areas as moral development and religious beliefs (e.g., Swan, 1980), goal-corrected attachment behaviors (e.g., Bowlby, 1969), and impulse control (e.g., Maccoby, 1980). Furthermore, forethought development may be involved in the cognitive domain of metamemory, in which it is first necessary for children to perceive why it is important to memorize (which is to be able to recall in the future) before they begin to utilize effective strategies (Flavell \& Wellman, 1977). These are only some examples of the pervasive control forethought may have over our cognitive and social functioning.

Although Arieti (1947) suggested that the development of forethought should be viewed from a life-span

The first author's mailing address is: Department of Psychology, University of Nebraska, Omaha, Nebraska 68182; the second author's is: Department of Psychology, San Jose State University, San Jose, California 95192. perspective, the following study represented an initial attempt to construct items that would measure forethought specifically in children and adolescents.

Several studies (Arieti, 1947; Sandham, 1980; Sandham \& Hicks, 1981) have suggested that forethought might be composed of as many as five dimensions, which include (1) the understanding of real-time consequences, (2) the anticipation of important future events, (3) the comprehension of death, (4) the understanding of cyclic variations in the natural environment, and (5) the sense of time. The purpose of this study was to construct a preliminary forethought scale (FS) that reflected the five dimensions suggested by Arieti. Prior to this research, there was no objective method of testing this construct. A large set of items was generated (Sandham, 1980), and then a factor-analytic study was conducted to determine the number of significant factors that might be involved in the measurement of forethought. On the basis of this analysis, a preliminary scale designed to measure forethought development in children and adolescents was constructed.

\section{METHOD}

\section{Subjects}

The subjects were 300 (150 male and 150 female) children, 50 ( 25 males and 25 females) from each of six age groups ranging from 3 and 4 to 13 and 14 years old (Sandham, 1980). The sample was drawn from private and public schools in the San Francisco Bay area. The subjects were selected on the basis of availability for participation in the study and parental permission to do so. 
Table 1

Rotated Oblique Factor: Pattern Matrix for All Males (20 Parcels)

\begin{tabular}{|c|c|c|c|c|}
\hline \multirow[b]{2}{*}{ Parcels } & \multicolumn{3}{|c|}{ Factor Loadings } & \multirow[b]{2}{*}{$\mathrm{h}^{2}$} \\
\hline & 1 & 2 & 3 & \\
\hline 1 & .94 & .06 & -.00 & .8872 \\
\hline 2 & .35 & .52 & -.07 & .3978 \\
\hline 3 & .72 & .09 & -.03 & .5274 \\
\hline 4 & .74 & -.11 & .03 & .5606 \\
\hline 5 & .31 & .11 & -.60 & .4682 \\
\hline 6 & .83 & -.05 & .11 & .7035 \\
\hline 7 & .75 & -.03 & .07 & .5683 \\
\hline 8 & .19 & .40 & -.30 & .2861 \\
\hline 9 & -.12 & .68 & -.17 & .5057 \\
\hline 10 & .07 & .54 & -.08 & .3029 \\
\hline 11 & .21 & .56 & -.04 & .3593 \\
\hline 12 & .01 & .04 & .08 & .0081 \\
\hline 13 & .16 & .42 & -.05 & .2045 \\
\hline 14 & -.02 & .61 & .19 & .4086 \\
\hline 15 & .41 & .34 & -.03 & .2846 \\
\hline 16 & .12 & .07 & .24 & .0769 \\
\hline 17 & .01 & .82 & .08 & .6789 \\
\hline 18 & .00 & -.07 & -.07 & .0098 \\
\hline 19 & .45 & .11 & -.14 & .2342 \\
\hline 20 & .32 & .45 & -.12 & .3193 \\
\hline
\end{tabular}

Note $-\Sigma L^{2}$ factor loadings: $1=4.0327 ; 2=3.0998 ; 3=.6594$ : $h^{2}=7.7919$. \% of total variance factor loadings: $1=20.16$; $2=15.49 ; 3=3.29: h^{2}=38.94$. \% of common variance factor loadings: $1=51.75 ; 2=39.98 ; 3=8.46: h^{2}=99.99$.

\section{Procedure}

The children responded to a 66-item questionnaire whose dichotomous variables reflected Arieti's (1947) five dimensions of forethought development.

\section{RESULTS}

A $66 \times 66$ intercorrelation matrix ${ }^{1}$ for all subjects was computed. (All statistics were performed using SPSS: Statistical Package for the Social Sciences, Nie, Hull, Jenkins, Steinbrenner, \& Bent, 1975.) Variables that were highly correlated and/or that measured similar or related areas were grouped into 20 parcels to obtain greater reliability than that offered by single test items (Horn \& Morrison, 1965).

From these combined scores, three (one each for all males, all females, and all subjects) $20 \times 20$ intercorrelation matrices between variables were computed. The extraction of the initial factors was accomplished by classical factor analysis. Principal factoring with iteration was performed using squared multiple correlations of each variable with the rest of the variables as estimates of communality. The resulting factors were then rotated by the oblique method. This method was chosen because it was assumed that the factors measuring forethought would be correlated.

The items for the finalized FS were selected according to the following procedure. First, the contents of the rotated factors for all males (see Table 1), for all females (see Table 2), and for all subjects (see Table 3) were inspected. The rotated-oblique pattern matrices for males and females produced similar factor loadings. In order to confirm this indication that sex differences

Table 2

Rotated Oblique Factor: Pattern Matrix for All Females (20 Parcels)

\begin{tabular}{crrrr} 
& \multicolumn{3}{c}{ Factor Loadings } & \\
\cline { 2 - 4 } Parcels & 1 & \multicolumn{1}{c}{$\mathrm{h}^{2}$} \\
\hline 1 & .79 & .05 & -.06 & .6302 \\
2 & .55 & .22 & -.02 & .3513 \\
3 & .67 & .07 & -.08 & .4602 \\
4 & .89 & .07 & .08 & .8034 \\
5 & -.08 & -.09 & -.88 & .7889 \\
6 & .80 & -.01 & -.03 & .6410 \\
7 & .87 & .04 & -.07 & .7634 \\
8 & .04 & .37 & -.52 & .4089 \\
9 & .03 & .85 & .15 & .7459 \\
10 & .42 & .18 & -.34 & .3244 \\
11 & .10 & .43 & -.32 & .2973 \\
12 & .09 & -.03 & -.26 & .0766 \\
13 & .25 & .10 & -.34 & .1881 \\
14 & .15 & .38 & -.16 & .1925 \\
15 & .09 & .20 & -.28 & .1265 \\
16 & -.03 & .08 & .03 & .0082 \\
17 & .01 & .47 & -.39 & .3731 \\
18 & .55 & -.15 & .01 & .3251 \\
19 & .13 & .04 & -.64 & .4281 \\
20 & .35 & .08 & -.35 & .1689 \\
\hline
\end{tabular}

Note $-\Sigma L^{2}$ factor loadings: $1=4.2214 ; 2=1.6003 ; 3=2.2803$ : $h^{2}=8.1020$. \% of total variance factor loadings: $1=21.10 ; 2=$ 8.00; $3=11.40: h^{2}=40.50$. \% of common variance factor loadings: $1=52.10 ; 2=19.75 ; 3=28.14: h^{2}=99.99$.

Table 3

Rotated Oblique Factor: Pattern Matrix for All Subjects (20 Parcels)

\begin{tabular}{crrrr} 
& \multicolumn{3}{c}{ Factor Loadings } & \\
\cline { 2 - 4 } Parcels & 1 & \multicolumn{1}{c}{. } & \multicolumn{1}{c}{3} \\
\hline 1 & .79 & .08 & -.08 & .6369 \\
2 & .43 & .41 & -.19 & .3891 \\
3 & .73 & .17 & -.05 & .5643 \\
4 & .78 & -.01 & .02 & .6089 \\
5 & .16 & .01 & -.65 & .4482 \\
6 & .85 & -.03 & .04 & .7250 \\
7 & .88 & -.02 & .00 & .7748 \\
8 & .08 & .29 & -.50 & .3405 \\
9 & -.19 & .69 & -.11 & .5243 \\
10 & .38 & .39 & -.20 & .3365 \\
11 & .12 & .57 & -.22 & .3877 \\
12 & .28 & .00 & -.04 & .0800 \\
13 & .26 & .30 & -.26 & .2252 \\
14 & .03 & .61 & .02 & .3734 \\
15 & .20 & .37 & -.16 & .2025 \\
16 & .09 & .28 & .13 & .1034 \\
17 & -.01 & .72 & -.15 & .5410 \\
18 & .57 & -.07 & -.02 & .3302 \\
19 & .27 & .06 & -.37 & .2134 \\
20 & .36 & .39 & -.23 & .3346 \\
\hline
\end{tabular}

Note $-\Sigma L^{2}$ factor loadings: $1=4.3966 ; 2=2.5985 ; 3=1.4448$ : $h^{2}=8.1399$. \% of total variance factor loadings: $1=21.98 ; 2=$ $12.99 ; 3=5.72: h^{2}=40.69$. \% of common variance factor loadings: $1=54.01 ; 2=31.92 ; 3=14.06: h^{2}=99.99$. 
Table 4

Matrix of Correlations Between Three Rotated Factors for All Subjects

\begin{tabular}{crcc}
\hline & \multicolumn{3}{c}{ Factor } \\
\cline { 2 - 4 } Factor & 1 & 2 & 3 \\
\hline 1 & & & \\
2 & .54 & & \\
3 & -.48 & -.45 & \\
\hline
\end{tabular}

within each factor were not significant, three nondirectional $\mathrm{t}$ tests for independent samples were conducted.

For Factor 1, a t test was conducted that combined parcels that had loadings on Factor $1 \geqslant .40$ from Tables 1 and 2. Parcels $1,2,3,4,6,7,15$, and 18 were combined. (Parcel 10 had a loading $\geqslant .40$ but was included with Factor 2 because it loaded heavier on Factor 2 and the variables within the parcel reflected the content of Factor 2.) The mean scores for these combined parcels were 14.71 for males and 14.99 for females $[t(298)=$ -.20 , n.s.].

For Factor 2, parcels with loadings $\geqslant .40$ were combined. Parcels 9, 10, 11, 13, 14, 17, and 20 were included. (Parcel 2 was included within Factor 1 because it loaded heavier on Factor 1 and the variables within the parcel reflected the content of Factor 1.) The mean scores on these combined parcels were 18.53 for males and 18.75 for females $[\mathrm{t}(298)=-.45$, n.s.] .

Parcels with loadings on Factor $3 \geqslant .40$ were combined, and only Parcels 5, 8, and 19 were included. The mean scores on these combined parcels were 9.35 for males and 9.55 for females [ $\mathrm{t}(298)=-1.15$, n.s.]

Because significant sex differences within factors were not found, only the pattern matrix for all subjects was used to determine significant factors. The correlation between each of these three factors is shown in Table 4. Only those parcels with factor loadings $\geqslant .45$ from Factors 1 and 2 and parcels with factor loadings $\geqslant-.45$ from Factor 3 were included in the FS. Twelve parcels, consisting of a total of 41 items, met this criterion.

Each factor was named to reflect the ability that it was thought to measure. Therefore, Factor 1 was named remote-future time comprehension, Factor 2, real-time consequences, and Factor 3, important future events. The three factors and the items found within each are shown in Table 5. The factors are listed in the order of the amount of variance accounted for, and the parcels are listed in the order of the magnitude of their loadings. Most of the common variance is accounted for by Factor 1, remote-future time comprehension.

\section{DISCUSSION}

The results of this study suggest that forethought may be a multidimensional construct, as suggested by Arieti (1947),
Table 5

Forethought Scale

Factor 1: Remote-Future Time Comprehension

Parcel 7

1. How many seasons are there in a year?

2 . How many months are there in each season?

Parcel 6

3. How many days are there in a year?

4. How many years are there in a decade?

5. How many years are there in a century?

6 . How often does the earth circle the sun?

Parcel 1

7. About how many hours will the sun stay set?

8. About how many hours will the sun stay risen?

9. If you place an ice cube in the sun about how long will it take the ice cube to melt?

10. How many hours are there in one day and night?

Parcel 4

11. How many months are there until next Christmas?

12. How many months are there until next Thanksgiving?

13. How many months are there until next Halloween?

Parcel 3

14. What month is Christmas in?

15. What month is Thanksgiving in?

16. What month is Halloween in?

Parcel 18

17. Next Christmas will come in the summer of winter?

18. Next Thanksgiving will come in the spring or the fall?

19. Next Halloween will come in the spring or the fall? Factor 2: Real Time Consequences

Parcel 17

20. What will happen to an ice cube if you leave it in the sun?

21. After you throw a ball up into the air, what will happen to it next?

22. What will happen to a seed after you plant it?

Parcel 9

23. Tomorrow will you get up in the morning or at night?

24. Tomorrow will you have breakfast in the morning or at night?

25. Tomorrow will you have dinner in the morning or at night?

26. Tomorrow will you go to school in the morning or at night?

Parcel 14

27. If plants do not get watered, what will happen to them?

28. If you step on an ant and crush it, what will happen to it?

29. What happens if you don't feed a dog or give him water? Parcel 11

30. In the summer the weather will be hot or cold?

31 . In the winter the weather will be hot or cold?

32. In the summer the weather will be sunny or rainy?

33. In the winter the weather will be sunny or rainy?

Factor 3: Important Future Events

Parcel 5

34. Will Christmas come once every year?

35. Will Halloween come once every year?

36. Will Thanksgiving come once every year?

Parcel 8

37. Do plants live forever?

38. Do all animals die?

39. Do you think you will die?

40. Does everyone die?

41. Can you stop yourself or someone else from dying? 
Sandham (1980), and Sandham and Hicks (1982). Although three factors were identified, Factor 1 accounts for more variance than Factors 2 and 3 combined. This finding is important because Factor 1 revealed that a specific kind of time comprehension, that is, remote-future time comprehension, may be an important indicator of forethought. In order for this to be verified, reliability and validity measures of this scale need to be conducted.

Another important finding is that this scale accounts for approximately $41 \%$ of the variance, which indicates the need for future research to focus on determining other possible predictors of this ability.

An interesting area of research might include naturalistic observations of mothers' increasing use of the future tense when speaking to infants, in order to document the onset of the understanding of the future (e.g., Ratner, 1980).

Finally, there has been reference in the literature to other than normal future-time concepts in people suffering from psychoses, depression, and neuroses (e.g., Melges, 1982). Forethought measurement could possibly be combined with other diagnostic tools to detect indications of those psychological disorders early in development.

\section{REFERENCES}

ArIeti, S. (1947). The process of expectation and anticipation: Their genetic development, neural basis and role in psychopathology. Journal of Nervous and Mental Disease, 96, 471-481. BowlBY, J. (1969). Attachment. New York: Basic Books.

Cotman, C. W., \& McGaugh, J. L. (1980). Behavioral neuroscience. New York: Academic Press.
Flavell, J., \& Wellman, H. (1977). Metamemory. In R. V. Kail \& J. W. Hagen (Eds.), Perspectives on the development of memory and cognition. New York: Erlbaum.

Horn, J. L., \& Morrison, W. L. (1965). Dimensions of teacher attitudes. Journal of Educational Psychology, 56, 118-125.

Macсову, E. (1980). Social development. New York: Harcourt Brace Jovanovich.

Melges, F. T. (1982). Time and the inner future: $A$ temporal approach to psychiatric disorders. New York: Wiley.

Nie, N. H., Hull, C. H., Jenkins, J. G., Steinbrenner, K., \& Bent, D. H. (1975). SPSS: Statistical Package for the social sciences. New York: McGraw-Hill.

RATNER, H. H. (1980). The role of social context in memory development. In M. Perlmutter (Ed.), Children's memory. San Francisco: Jossey-Bass.

SANDHAM, L. J. (1980). Age dependent forethought in children. Unpublished master's thesis, San Jose State University, San Jose, California.

Sandham, L. J., \& Hicks, R. A. (1982). Forethought development in children and adolescents. Bulletin of the Psychonomic Society, 20, 77-78.

Swan, L. W. (1980). Our Promethean sense: $A$ view of behavior and human evolution. Unpublished manuscript.

\section{NOTE}

1. Intercorrelation matrices are available through Resources in Education, May 1983, Document No. ED 224597.

(Manuscript received for publication November 7, 1983.) 